\section{In tern ationa l \\ Journal of}

Medical

and Surgical Sciences

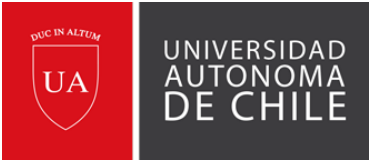

\title{
Human rights abuses experienced by people who use drugs. A Nigeria-focused review.
}

\author{
Ikenna Daniel Molobe. ${ }^{1}$
}

\section{ABSTRACT}

Drug abuse is a global health issue. Even though people use drugs for different reasons, sometimes drugs become central to their lives and they believe that they cannot live without them. Such people are dependent on the drugs they use. The social stigma of alcohol, and other drugs, use remains in society. People who use or abuse drugs are highly stigmatized, which often prevents them from being included and accepted within society and their communities. People see them as irresponsible and a threat to the environment. Some families cannot acknowledge that a family member uses drugs, or provide them with proper treatment in hospitals or rehabilitation centers because of the accompanying stigma, which the family may not like to be associated with. Many people who use drugs are jobless and poor, and have been disengaged from their families, education and training. They may resort to self-medication when they need medical attention. Some of them cannot afford expensive medical services and may die as a result of treatable illnesses. In some cases, medical service providers can be reluctant to admit people who use drugs to their facilities and, thus, they face compounding rejection. This paper describes human rights abuses occurring among drug users, and also reviews the available literature on human rights violations experienced by people who use drugs with focus in the Nigerian socio-cultural environment.

Keywords: Human Rights, Drug use \& abuse, Nigeria.

\section{INTRODUCTION}

Drug use is a worldwide phenomenon, and people use drugs for different reasons: for example, to have fun, to cope with stress, to deal with pain, to sleep or stay awake, to enhance sex, and to celebrate. Most people who experiment with drug use tend to realize that they do not want to become 'hooked' or dependent on drugs to meet their needs, and cease use. For some, drugs become central to their lives and they believe that they cannot live without them. Such people are dependent on the drugs they use. They also recognize that their use of drugs brings many extra difficulties in their lives, for example, finding money to buy drugs, conflicts with family and friends, loss of educational and employment opportunities, violence, imprisonment, and even serious illnesses and death. It is a tragedy that a great number of HIV infections are associated with the use of drugs, especially through injecting drugs and unsafe sexual activity when intoxicated. Hepatitis $C$ is also endemic among people who inject drugs. These diseases place a huge emotional and financial strain on loved ones, the community and the State (Wolitski et al, 2009).

Human rights abuses, denial of care and violence directed at drug users have been found to impact the prevention efforts and social status of people using drugs (Krieger, 1999). In Nigeria, drug control laws are often in conflict with harm reduction policies, thus increasing the likelihood of rights abuses against drug users. There have been numerous reports, formal and informal, of frequent rights abuses among drugs users, as well as societal stigma that lead to the limitation of many of their rights. Drug users are also frequently denied the basic right to care. In line with the Human Rights conventions and treaties and the Convention on the Rights of the 
Child (CRC), there should be respect of the human rights of people who use drugs, and abolishment of abusive practices carried out for the sake of treatment such as forced detention, forced labour, and physical or psychological abuse that contravene human rights standards and norms or that remove the right to self-determination (Human Rights Watch, 2011).

This paper describes human rights abuses occurring among drug users, and also reviews the available literature on human rights violation experienced by people who use drugs with focus in the Nigerian socio-cultural environment.

\section{THE EFFECTS OF RECURRENT RIGHTS ABUSES AMONG DRUG USERS}

The social stigma of alcohol, and other drugs, use remains in society. People who use drug are highly stigmatized, which often prevents them from being included and accepted within society and their communities (Ahern et al, 2007). In Nigerian society, people see drug users as irresponsible and a threat to the environment. Some families cannot acknowledge that a family member uses drugs, or provide them with proper treatment in hospitals or in rehabilitation centers because of the accompanying stigma, which the family may not like to be associated with.

Also in Nigeria, many people who use drugs are jobless and poor, and have been disengaged from their families, education and training. They may resort to self-medication when they need medical attention. Some of them cannot afford expensive medical services and may die as a result of treatable illnesses. In some cases, medical service providers can be reluctant to admit people who use drugs to their facilities and, thus, they face compounding rejection. Societal stigma, discrimination and social exclusion of people who use drugs from their families, communities and services should be a concern for everybody; especially, as all people have right to health. Many of the people who take drugs, and later become dependent on them, do so as a result of frustration, unemployment, conflicts at home, peer influence, or lack of parental guidance. They do not always intentionally go into the scene of drug use. This reveals that they need help, should not experience discrimination and, like all people, have an expectation to have their human rights realized (Kaplan, 2009).

When the family and the society show love, concern and care for those that have been trapped in this circumstance, most of their problems will be solved. Some can easily recover when the society shows concern. It is when individuals and the community do not care for such people, "after all, they are nuisance to the society", that the incidence of drug use continues to rise. When people who use drugs cannot see anybody that shows concern and love for them, they may suffer more psychological trauma and this can increase their drug use and, in some cases, they may consider attempting suicide or just not care if they live or die (Clancey \& Howard, 2006).

Reviews of studies by Jürgens et al. (2010) on the link between human rights abuses experienced by people who use drugs, vulnerability to HIV infection and access to services revealed widespread human rights abuses, which increased vulnerability, especially for women and children. Most people who are recovering from drug use and its effects and who have gone through counseling, rehabilitation and treatment find it difficult to reintegrate into society because the same society still tends to see them as nuisance or criminal, and, as many have been denied jobs, they may return to use of drugs to cope.

This approach worsens social exclusion and discrimination, making it even harder for rehabilitation, and exposes young people to violence and, even worse, more rooted drug users. Young people who use illicit drugs face daily harassment, discrimination, and abuse. Most incidents go unreported, due to fears of reprisal and other harmful physical, mental, social, or legal consequences (Kaplan, 2009). Often, law enforcement and the rest of society do not recognize the basic rights of people who use drugs, and blame the victim for any abuse that stems from drug use. Moreover, some government laws and policies directly violate the rights of people who use drugs or create the conditions for these violations to occur. Traditional approaches to drug control in many countries, such as in Nigeria, include physical and psychological violence by forced drug 'rehabilitation' in quasi-prison settings, whose programs lack therapeutic motivation and social benefits.

\section{THE RIGHT TO HEALTH, SOCIAL SECURITY AND ADE- QUATE STANDARD OF LIVING}

Societal stigma, discrimination and social exclusion of people who use drugs from their families, communities and services should be a concern for everybody; especially, as all people have right to health (Ahern et al., 2007). People have a right to health and freedom from discrimination regardless of age, HIV status, drug use, sexual orientation and gender. The rights of people who use drugs, including those detained in prisons, detention and treatment centres, must be respected, protected and fulfilled. With respect to drug treatment, in line with the right to informed consent, medical treatment, drug dependence treatment and voluntary HIV testing should not be forced on patients. In cases of treatment refusal, medical skills are needed to seek consent and make the patients understand the need for treatment or testing for HIV. 
In spite of this, the following recommendations must be considered:

1. Review of Policies: The federal government of Nigeria and other stakeholders should revisit and review policies to reflect human rights expectations, including those that are victims of drug use. Such policies should be reflected in Drug control policy and other policies, such as health, education, etc.

2. Public Enlightenment and Advocacy: In order to create awareness to stop violation of drug users' rights, it is recommended that awareness and advocacy programs from the government, civil society, media and private sector should also focus on proper education and enlightenment of the public to understand and respect freedom of rights of people that use drugs.

\section{Awareness Training for Law Enforcement Agencies: Continuous training on human rights expectation regar- ding drug users should be instilled in law enforcement training programs to reduce punitive mandatory punish- ments that violate the rights of people that use drugs.}

4. Prisons services should always investigate individual cause of offence to examine its relation to drug use and provide special and effective drug rehabilitation for those that use drugs, as different people require different therapeutic approaches or attention for rehabilitation.

5. There should be extensive scientific-based research on mental health status in the context of rights abuses among drug users to establish supporting facts for reviewing policies.

Drug use has been a major problem in many societies. Many people, especially young people, have lost their lives as a result of drug use. It is the everyone's duty to be involved in the fight against destructive drug use. We should remember that the society cannot be at peace if drugs use is prevalent, and those who use them excluded from participation and having their health and other rights met. Everybody is affected because some drug users may commit robberies, vandalize properties, and provoke road accidents. Likewise, they themselves may become the victims of criminals who exploit them, and also be exposed to preventable infections that may cost them their lives.

\section{CONCLUSION}

While drugs may have a pernicious effect on individual lives and society, the excessively punitive system has not achieved its stated public health goals, and has resulted in countless human rights violations.

\section{REFERENCES}

Ahern J, Stuber J, Galea S. Stigma, discrimination and the health of illicit drug users. Drug Alcohol Depend. 2007;88(2-3):188-96.

Clancey G, Howard J. Diversion and criminal justice drug treatment: mechanism of emancipation or social control? Drug Alcohol Rev. 2006;25(4):377-385.

Human Rights Watch, World Report Chapter: Mexico. 2011. Available at https://www.hrw.org/world-report/2011/country-chapters/mexico.

Jürgens R, Csete J, Amon J, Baral S, Beyrer C. () Drugs, HIV, and Human Rights. Lancet 2010;376(9739): 475-485.

Kaplan K. Human Rights Documentation and Advocacy: A guide for organizations of people who use drugs. New York: Open Society Institute, 2009. Available at: https://www.opensocietyfoundations.org/publications/human-rights-documentation-and-advocacy-guide-organizations-people-who-use-drugs.

Krieger N. Embodying inequality: a review of concepts, measures, and methods for studying health consequences of discrimination, Int J Health Serv. 1999;29(2):295-352.

Wolitski RJ, Pals SL, Kidder DP. Courtenay-Quirk C, Holtgrave DR. The effects of HIV stigma on health, disclosure of HIV status, and risk behavior of homeless and unstably housed persons living with HIV. AIDS Behav. 2009;13(6):1222-32. 